\title{
Natural Fibre Insulation Materials: Use of Textile and Agri-food Waste in a Circular Economy Perspective
}

\author{
Lorenzo Savio $^{1}$ (1) $\cdot$ Roberto Pennacchio ${ }^{1} \cdot$ Alessia Patrucco $^{2} \cdot$ Valentino Manni $^{1} \cdot$ Daniela Bosia $^{1}$
}

Received: 7 June 2021 / Revised: 12 October 2021 / Accepted: 24 October 2021 / Published online: 8 January 2022

(c) The Author(s) 2021

\begin{abstract}
Fibrous materials are among those most used for the thermal and acoustic insulation of building envelopes and are also suitable for a wide range of applications. In building construction, the demand for products with low environmental impact - in line with the Green Deal challenge of the European Community - is growing, but the building market is still mostly oriented towards traditional products, missing the many opportunities for using waste materials from existing industrial production. The paper presents the experimental results of new thermal and acoustic insulation products for building construction and interior design, based on previous experiences of the research group. They are produced entirely using waste sheep's wool as a "matrix" and other waste fibres as "fillers". The materials proposed originate from textile and agri-industrial chains in the Piedmont region and have no uses other than waste-to-heat biomass. The panels have characteristics of rigidity, workability, and thermal conductivity that make them suitable for building envelope insulation.
\end{abstract}

Keywords Sheep wool $\cdot$ Circular economy $\cdot$ Insulation panel $\cdot$ Sustainable architecture $\cdot$ Textile wastes $\cdot$ Natural fibres . Agri-food wastes

\section{Introduction}

Since the end of the last century, the cultural debate on energy and environmental issues has heavily involved the construction world. According to the ECORYS report (2014), in European countries, about $40 \%$ of total energy consumption, $30 \%$ of greenhouse gas emissions, and the third part of the total wastes, are attributable to the construction sector. On a global scale, the situation is equally critical (Fig. 1) (UNEP - United Nations Environment Programme 2020). If we then consider the demographic increase and the urbanisation of developing countries, the pressure on the environment will even increase.

The framework outlined requires the identification of solutions capable of drastically reducing the consumption of

This article is part of the Topical Collection on Natural Fibers: Materials of the Future

Lorenzo Savio

lorenzo.savio@polito.it

1 DAD, Department of Architecture and Design, Politecnico Di Torino, Viale Mattioli 39, 10125 Torino, Italy

2 STIIMA, CNR, C.So G. Pella, 16 - 13900 Biella, Italy resources and the consequent environmental impact, focusing more attention on the protection of natural raw materials. Consequently, the sector's attention must be increasingly concentrated on an environmentally sustainable approach that takes into account the components and materials used in the construction of buildings and, their entire life cycle in general. It is a matter of overcoming the traditional linear economic model based on the "extract, produce, use and discard" approach, which requires large supplies of cheap materials and energy, to move to an alternative model of circular economy which, by reducing waste, differentiating suppliers and extending the lifespan of consumer products, seeks to rethink economic development as independently as possible of the consumption of non-renewable resources (European Parliament 2015).

Undoubtedly, the transition to a circular economy, by means of efficient use of natural resources and increased use of secondary raw materials, can offer numerous advantages, including reduced pressure on the environment, improved certainty of the supply of raw materials, technological innovations and new market and employment opportunities. There have been various initiatives at European level to promote environmental sustainability projects: from the first directives that focused on the energy 


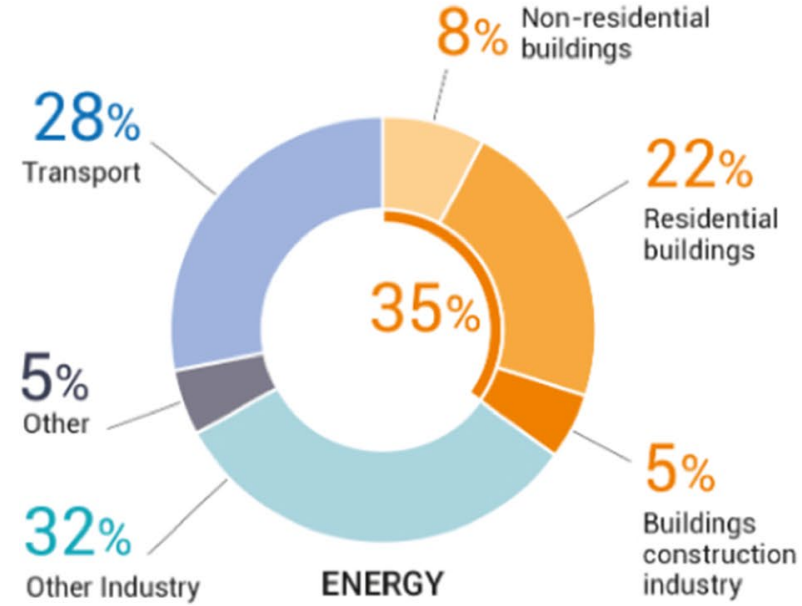

Fig. 1 Global share of buildings and construction final energy and emissions, 2019 (UNEP 2020). Buildings construction industry is the portion (estimated) of overall industry devoted to manufacturing building construction materials such as steel, cement and glass.

efficiency of buildings to the most recent ones, aimed at the environmentally efficient use of building materials and the need to implement virtuous processes of reuse, recovery and recycling of products, towards the nearly-zeroenergy buildings by 2050 (European Commission 2019).

The EU's legislative impulse towards sustainability was entrusted to the Green Public Procurement (GPP) environmental policy instrument. With the advent of GPP, which regulates procurement by the public administration, sustainable technologies and the development of environmentally sound products are encouraged in several sectors. Thanks to the legislative impulse, the construction sector, usually characterised by a certain inertia when it comes to innovation, is moving towards technologies, products and building systems with low environmental impact and certified energy performance.

The Italian legislative framework conforms to European standards with the adoption of the "National Action Plan on Green Public Procurement", which defines national goals and identifies the Minimum Environmental Criteria (CAM - Criteri Ambientali Minimi) to be observed for different categories of goods, services and operations. The CAMs are the environmental and ecological requirements defined by the Ministry for the Environment, Land and Sea (MATTM - Ministero dell'Ambiente e della Tutele del Territorio e del Mare) aimed at guiding public administrations towards the rationalisation of consumption and purchases, providing guidelines for the identification of design solutions, products or services more environmental-friendly, paying particular attention to the entire life cycle of a product or service, from its disposal

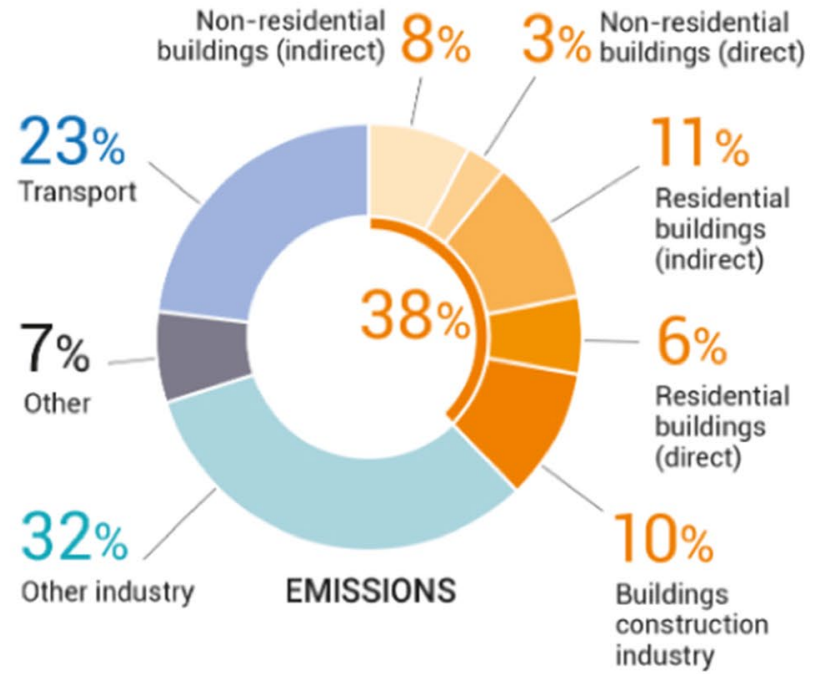

Indirect emissions are emissions from power generation for electricity and commercial heat. Sources: (IEA 2020d; IEA 2020b). All rights reserved. Adapted from "IEA World Energy Statistics and Balances" and "Energy Technology Perspectives"

to its availability on the market, and the transparency of the production chain.

The effectiveness of the CAM has been ensured thanks to article 18 of Law no. 221 of 28 December 2015 and, subsequently, article 34 on "energy and environmental sustainability criteria" of Legislative Decree 50/2016 "Tender Code" (as amended by Legislative Decree 56/2017), which made their application by all contracting stations mandatory. The mandatory and systematic application of CAM within public procurement will guarantee the reduction of environmental impacts, through the dissemination of environmentally sustainable technologies and products. With the Ministerial Decree of 11 October 2017 "Minimum environmental criteria for the awarding of design services and works for the new construction, renovation and maintenance of public buildings", the construction sector must also comply with CAM requirements that reward the most sustainable or energyefficient materials belonging to a circular economy.

Consequently, the recycling of materials becomes fundamental: it is precisely through the use of discarded materials that a virtuous circle is set in motion from many points of view, including economically, in compliance with the criteria of a sustainable, low-impact economy.

The specifications indicated in Chapter 2.4 "Technical specifications of building components" of the Ministerial Decree of 11 October 2017 (MATTM 2021) go in this direction. As well as requiring the absence of hazardous substances, they also require:

- that at least $50 \%$ of the construction components and prefabricated elements should be suitable, for selective 
demolition and for recycling or reuse, at the end of their life cycle;

- that reused or recycled materials account for at least $15 \%$ of the weight, assessed on the total of all the materials used.

To this end, what are known as "secondary raw materials" from demolitions, such as glass, metal and cardboard scraps from urban waste collection or offcuts from various industrial sectors, are valuable sources as, thanks to the synergy between scientific research, the willingness of eco-sensitive entrepreneurs and increasingly restrictive legislation guaranteeing their suitability for use, they are now transformed into products for the building industry.

With the entry into force of the $110 \%$ Superbonus, introduced by the "Relaunch" decree-law of 19 May 2020, which aims to make buildings safer and more efficient, the impact of the Ministerial Decree of 2017, conceived in relation to public construction, is also extended to private construction.

Thermal insulation of the building envelope is one of the key operations to qualify for the Superbonus. Specifically, for thermal and acoustic insulation materials (as indicated in point 2.4.2.9 of the Technical Specifications of building components of the Ministerial Decree of 11 October 2017), safety requirements are established (e.g. they must not contain substances that are harmful to the environment) and specific percentages of recycled material that they must contain on the basis of their composition and type (e.g. rockwool panels must contain at least $15 \%$ recycled material) are identified.

\section{Low Environmental Impact Thermal-Acoustic Insulation Panels}

\section{The "Open Recipe" Concept}

The reference framework described and the adoption of the CAMs provide clear guidance for the building products market. In the case of thermo-acoustic insulation, the CAMs encourage the choice of products that use recycled materials or low-impact and renewable raw materials (fibres of plant origin or offcuts from industrial processes in other supply chains). For example, glass wool products must consist of $60 \%$ recycled and/or reused material by weight of the finished product, and expanded polystyrene (EPS) insulation must consist of 10 to $60 \%$ recycled and/ or recovered material, depending on the technology used in production, measured by weight of the finished product. In general, the current legislative framework considers environmentally friendly building products that use materials that can regenerate in the short term, fully or partially recycled materials, local materials made with locally manufactured or processed raw materials. Their production chain is also characterised by a limited and circumscribed number of steps, with the consequent containment of the cost of the products and mitigation of the environmental and social impact of transport by reducing the distance, and therefore the promotion of local economies.

This research, carried out with the aim of producing thermo-acoustic insulation panels made of natural fibres, using residues or products, originating from the agri-food and textile sectors in the Piedmont region, falls within this context. The research follows on from previous experience in the production and testing of insulating panels made of sheep's wool, Cartonlana (Bosia et al. 2015), and of wool and hemp, Fitness (Pennacchio et al. 2017).

Cartonlana and Fitness are rigid thermoacoustic insulating panels for buildings, made with natural waste materials coming from agri-food supply chains of the Piedmont region. Cartonlana is made from $100 \%$ sheep's wool not suitable for use in the textile industry, while Fitness is made from 50\% sheep's wool and 50\% hemp fibres. The sheep wool used is a waste from the sheep farming sector, which produces milk and meat; recovering it in the production of insulating panels allows to avoid its disposal, which is often incongruous and harmful to the environment, as sheep wool is usually burned or buried. The specific manufacturing process gives rigidity to the panels and eases its installation and incorporation into building envelope stratigraphies, allowing the application of dry and disassemblable technologies. Panel's rigidity is achieved by using a chemical treatment acting on the keratin content of the sheep's wool and it's a characteristic that wool and hemp insulation products available on the market usually do not possess. In Fitness, the possibility of mixing sheep wool with other materials has been successfully tested, reaching even more satisfactory performances, in term of acoustic insulation and workability.

Based on these experiences, the research group has developed a new production concept, able of interpreting the requests deriving from the European Green Deal even more effectively. In particular, after the positive results obtained with wool and hemp panels, several possibilities of using other waste materials from the local agri-industrial production chains were assessed, with the aim of minimising the environmental impact of the final product and fully exploiting waste that is already available, in keeping with the principles of the circular economy.

The concept developed for the new experiments envisages an "open recipe" (Savio et al. 2019) in which the sheep's wool treated with the process tested with Cartonlana and Fitness becomes the "matrix" into which other materials, which must meet the following requirements, can be incorporated as "fillers" (Fig. 1): 
- They must be waste, preferably of natural origin, already available in the reference territory, originating from existing agri-industrial and textile productions, ensuring constant availability over time;

- They must not be edible and must not be used for any other purpose, except for waste-to-energy as biomass;

- They must have a fibrous structure, compatible with incorporation with sheep's wool fibres;

- They must not undergo complex transformation processes before being used, other than simple cutting and defibration operations.

The "open recipe" concept presents certain advantages over previous experimentations:

- Less use is made of sheep's wool, which is locally available, but for which there is currently no efficient collection chain capable of responding adequately to industrialscale production;

- Keeping as a reference the fulfilment of the physical and technical requirements needed for the use of the panels as thermo-acoustic insulators (according to a principle of "sufficiency"), a wide variety of waste can be used, allowing great flexibility in adapting to availability, which may vary over time.

\section{The Production Process and Selection of Materials}

The new experiments were preceded by a regional mapping of materials suitable for use as fillers. The following materials were selected as possible charges for the panels: waste from chestnut debarking, dry leaves and stems from the bean plant, bracts and dry residues from corn, sawdust from coarse-cut wood processing, rice straw. In addition, dust residues from wool processing have been selected from textile mills in the Biella area, which mainly process highquality imported cashmere. They are of twofold interest for the production of panels: they can be used as fillers or partially replace the rough wool fibres in the matrix.

These materials were used to produce numerous small samples, applying a unique production process, which envisages the following steps:

- Preparation of the materials and dry blending. The sheep's wool used as matrix is washed. Plant residues do not affect the production of the panels, the fibres are simply opened to facilitate the integration of the filler. The materials used as filler are cut and defibrated to a size suitable for mixing with the wool. The textile powders do not require any special processing at this stage;

- Chemical treatment of the fibres. The chemical bath (basic solution) is prepared separately, heated and added to the matrix and filler mixture (Table 1);

- Neutralisation by means of an acid bath and draining of the mash (matrix and wet filler);

- Transfer of the mash to a container which will give the sample its final shape;

- Drying in an oven until the sample is completely dry, removal from the mould.

Although at this stage an LCA has not been completed with production costs, some general considerations can be made on the environmental characteristics of the product and of the production process. The materials used are wastes that have no other uses than disposal or waste-to-energy (for those of agricultural origin). In many cases, reusing them avoids improper disposal. The amount of sodium hydroxide used is minimal (Table 1) and it is reasonable to consider reducing it further. A production process is being tested in which the neutralization phase is eliminated and the chemical bath can be recovered and reused for multiple productions. The basic bath with sodium hydroxide, however, can be neutralised with hydrochloric acid at the end of the

Table 1 Specifications on the chemical treatment

\begin{tabular}{|c|c|c|c|c|c|c|c|}
\hline \multirow[t]{2}{*}{ Panel samples } & \multirow{2}{*}{$\begin{array}{l}\text { Matrix/ } \\
\text { filler ratio }\end{array}$} & \multirow[t]{2}{*}{ Matrix } & \multirow[t]{2}{*}{ Filler } & \multicolumn{4}{|l|}{ Chemical treatment (basic solution) } \\
\hline & & & & Liquor ratio & $\begin{array}{l}\text { Sodium hydroxide } \\
\text { concentration }\end{array}$ & Temperature & Time \\
\hline & - & {$[\mathrm{g}]$} & {$[\mathrm{g}]$} & [g: ml] & {$[\mathrm{g} / \mathrm{l}]$} & {$\left[{ }^{\circ} \mathrm{C}\right]$} & [min] \\
\hline AGROTESs A & $2: 1$ & 250 & 125 & $\begin{array}{l}\text { 1:40 } \\
\text { ( } \mathrm{g} \text { of wool: } \mathrm{ml} \text { of solution) }\end{array}$ & 1.25 & 60 & 15 \\
\hline AGROTESs B & $2: 1$ & 250 & 125 & $\begin{array}{l}\text { 1:40 } \\
\text { ( } \text { of wool: } \mathrm{ml} \text { of solution) }\end{array}$ & 1.25 & 60 & 15 \\
\hline AGROTESs C & - & - & 250 & $\begin{array}{l}\text { 1:40 } \\
\text { ( } \mathrm{g} \text { of textile wastes: } \mathrm{ml} \text { of solution) }\end{array}$ & 10.00 & 60 & 10 \\
\hline AGROTESs C1 & - & - & 250 & $\begin{array}{l}\text { 1:20 } \\
\text { (g of textile wastes: } \mathrm{ml} \text { of solution) }\end{array}$ & 10.00 & 60 & 5 \\
\hline
\end{tabular}


production process, obtaining a solution with sodium chloride, which is not harmful to the environment. The most impactful step on an energy-environmental level is certainly the drying phase, which was made for the samples using an electric oven.

The production process was applied, with appropriate adaptations to the cutting methods, mixing times and quantity of chemical baths for the different materials. The production of the preliminary samples made it possible to select the most suitable materials for use as "fillers", choosing those that were easier to work with, that could be mechanically incorporated with the wool fibres, creating samples that were more suitable for use in the building industry (Fig. 2). Rice straw, bracts and chopped corn residues and textile dusts were selected for the next experimental phase (Fig. 3). AGROTESs samples were made from these materials, with dimensions and characteristics useful for the tests to measure thermal conductivity (Figs. 4-5).

\section{The Thermal Performance of AGROTESs Samples}

\section{Steady-State Thermal Tests and Discussion}

Four AGROTESs samples, AGROTESs A, waste wool fibres mixed with rice straw fibres, AGROTESs B, waste wool fibres mixed with chopped corn, and AGROTESs C and C1 obtained from waste wool textile powders, prepared at the
CNR laboratories in Biella (BI), underwent unidirectional steady-state thermal tests. The sample size, initially measuring $20 \times 15 \mathrm{~cm}$, was reduced to approximately $15 \times 15 \mathrm{~cm}$, even if with certain slight differences, for test procedure reasons.

The tests were performed through the guarded ring hot plate method (ISO 8302:1991; UNI EN 12,667:2002), at the Tecno Piemonte S.p.a. laboratories, in Biella (BI). The apparatus used was a $\lambda$ - meter EP 500 v.C Lambda-Messtechinik $\mathrm{GmbH}$ model and the test temperature was $20^{\circ} \mathrm{C}$, while the two apparatus plates were set to a temperature difference $\Delta \mathrm{T}$ of $15 \mathrm{~K}$ degrees. It was not possible to complete the thermal tests of sample $\mathrm{C}$, as it showed highly brittle behaviour and poor particles' cohesion; moreover, it was estimated that the presence of fissures on the surface would have highly influenced the heat flow through the sample and the reliability of thermal measures.

The tests performed on AGROTESs samples A, B and $\mathrm{C} 1$ allowed the measurement of thermal conductivity $\lambda[\mathrm{W} /$ $\mathrm{mK}]$, thermal resistance $\mathrm{R}\left[\mathrm{m}^{2} \mathrm{~K} / \mathrm{W}\right]$, thermal transmittance $\mathrm{U}\left[\mathrm{W} / \mathrm{m}^{2} \mathrm{~K}\right]$, bulk density $\left[\mathrm{kg} / \mathrm{m}^{3}\right]$ and mass $[\mathrm{g}]$; the results are shown in Table 2. All three samples were dried in oven before performing the test.

Sample A showed the most interesting $\lambda$ value, while samples B and C1 associate higher thermal conductivity with higher density values, which could convey good diffusivity performance to the panels, which would be useful in summer to prevent buildings from overheating. The thermal conductivity values of AGROTESs samples
Fig. 2 Examples of wasted materials from local industrial supply chains (Piedmont Region): bean dry plant (a), chestnut bark (b), textile dust (c), corn plant bracts (d)
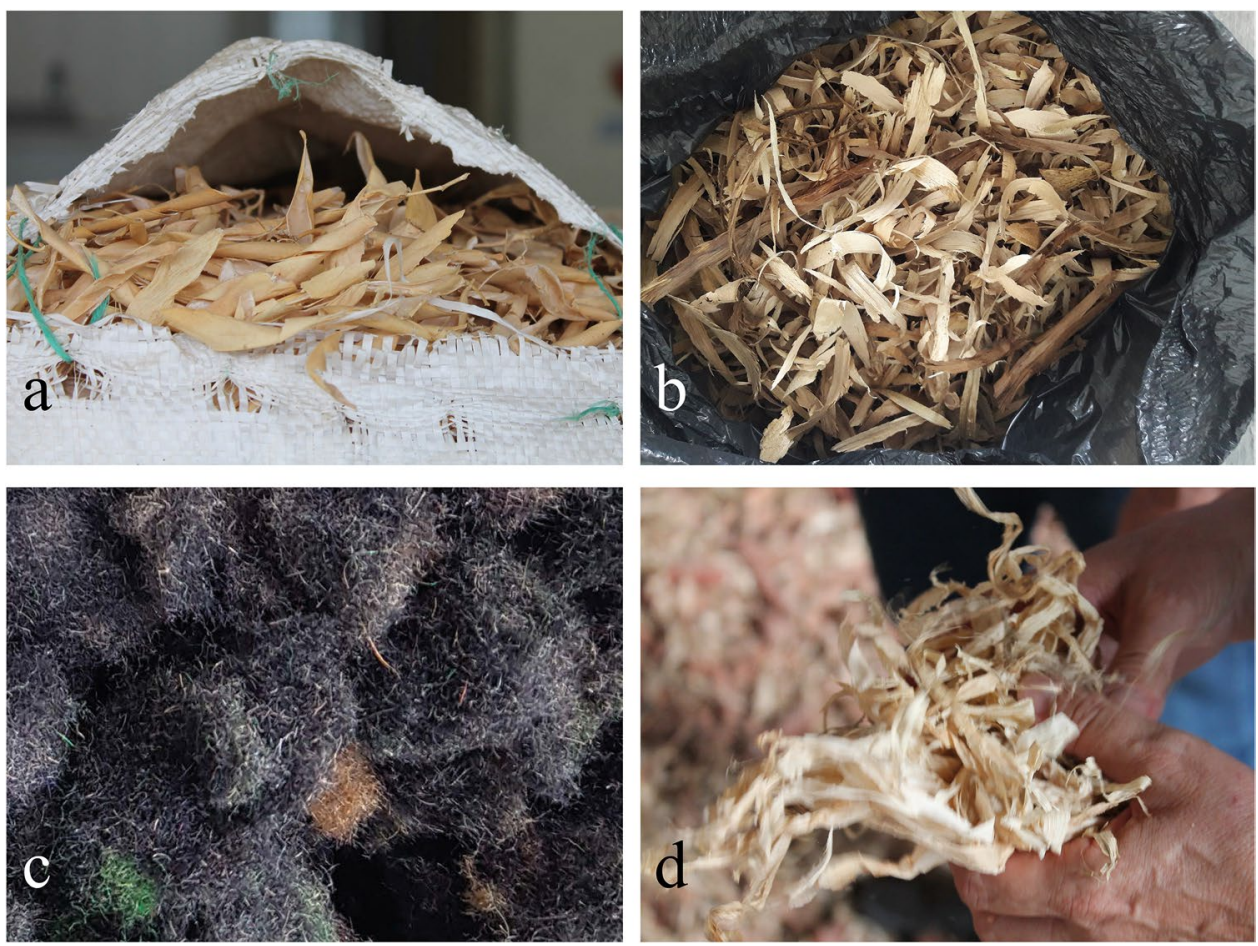
Fig. 3 Preparation of small preliminary samples using waste materials from local industrial supply chains (Piedmont Region) selected according to the concept of the "open recipe". Corn Bracts (a-c-e), bean dry plant (b), corn bracts-bean dry plant—wood sawdust (d), almond shell (f)
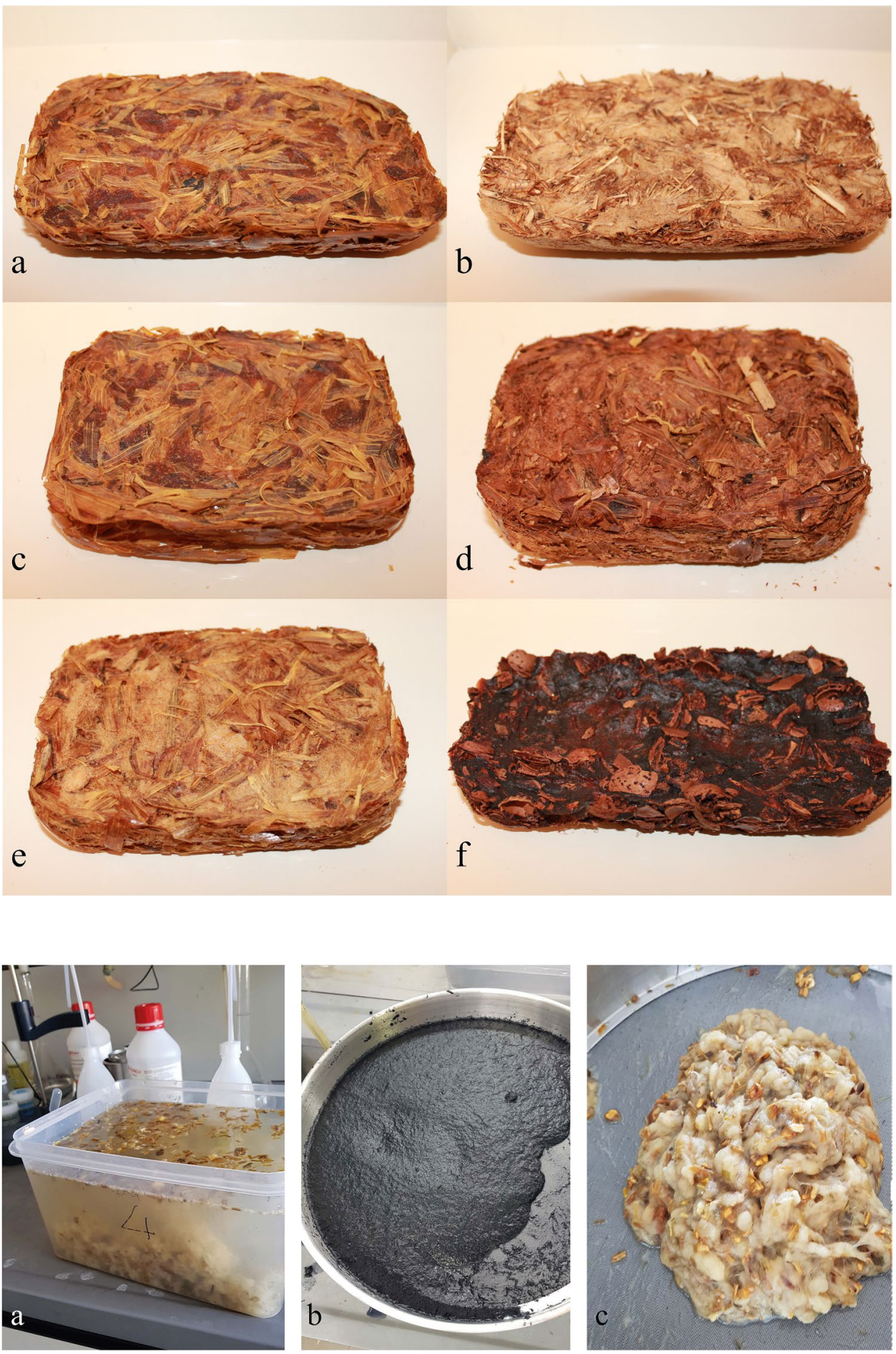

Fig. 4 AGROTESs samples production. Examples of production phases: chemical treatment of the fibres (a-chopped corn) and draining of the mash after neutralization in acid solution (b-textile wastes, c-chopped corn) proved slightly higher than those of Cartonlana and FITNESs, similar insulating panels previously realised by the authors (Bosia et al. 2015; Pennacchio et al. 2017), and of the main thermal insulation panels made from natural materials already available on the market. On the other hand, both the $\lambda$ and bulk density values seem to perfectly match the mean values of the research products for thermal insulation from waste materials and by-products of agriindustrial production chains. 

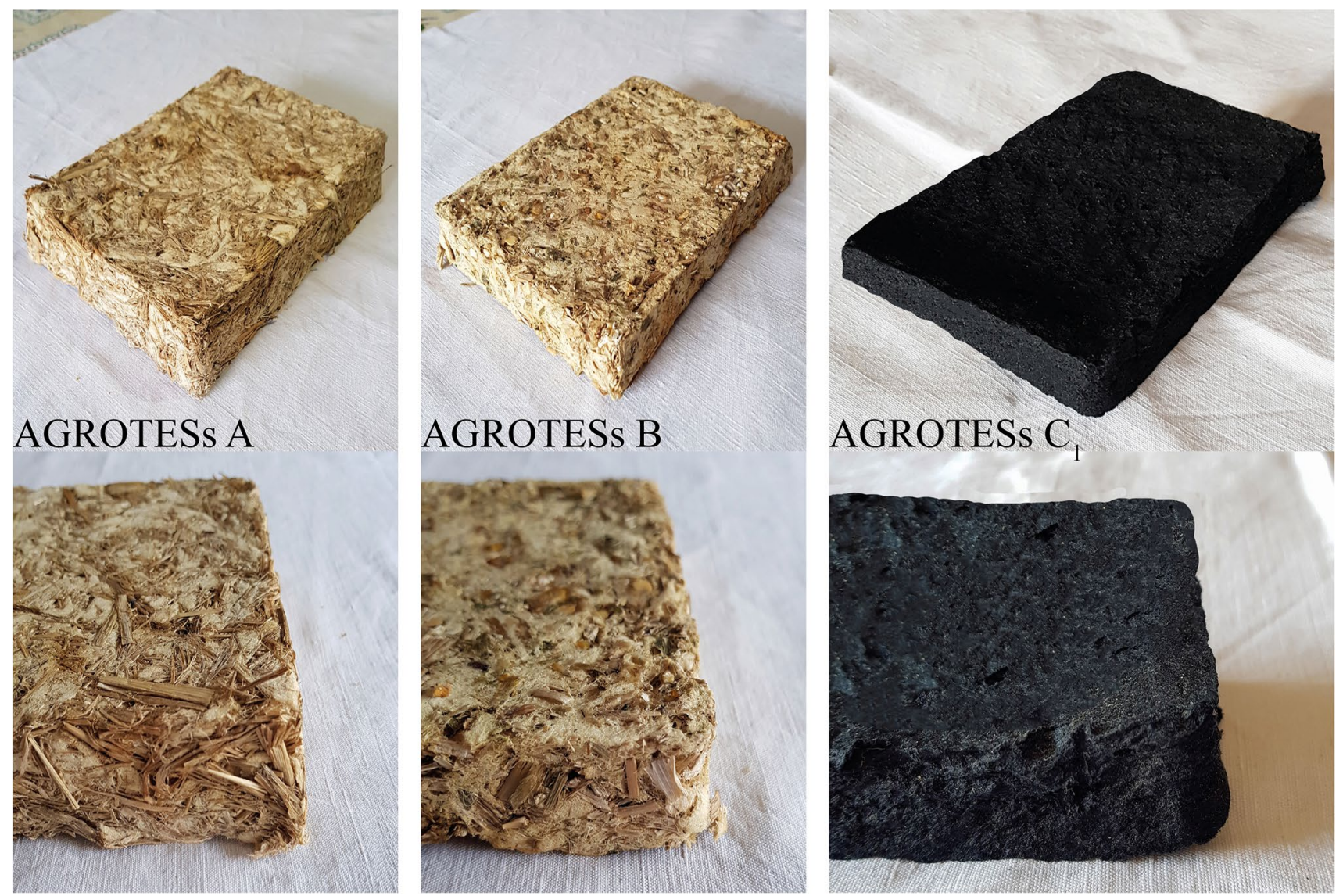

Fig. 5 AGROTESs samples. AGROTESs A: rice straw; AGROTESs B: chopped corn; AGROTESs C1: textiles wastes

Table 2 Thermal measurements of AGROTESs samples

\begin{tabular}{llllllc}
\hline Panel samples & $\begin{array}{l}\text { Dimensions } \\
{[\mathrm{cm}]}\end{array}$ & $\begin{array}{l}\text { Mass } \\
{[\mathrm{g}]}\end{array}$ & $\begin{array}{l}\text { Bulk density } \\
{\left[\mathrm{kg} / \mathrm{m}^{3}\right]}\end{array}$ & $\begin{array}{l}\lambda \\
{[\mathrm{W} / \mathrm{mK}]}\end{array}$ & $\begin{array}{l}\mathrm{R} \\
{\left[\mathrm{m}^{2} \mathrm{~K} / \mathrm{W}\right]}\end{array}$ & $\begin{array}{l}\mathrm{U} \\
{\left[\mathrm{W} / \mathrm{m}^{2} \mathrm{~K}\right]}\end{array}$ \\
\hline AGROTESs A & $15 \times 15 \times 3.5$ & 161 & 204 & 0.054 & 0.648 & 1.54 \\
AGROTESs B & $15 \times 14 \times 3.5$ & 141 & 249 & 0.063 & 0.429 & 2.33 \\
AGROTESs C & $15 \times 15 \times 2.2$ & 134 & 203 & - & - & - \\
AGROTESs C1 & $14.5 \times 13.5 \times 2.2$ & 136 & 240 & 0.061 & 0.475 & 2.11 \\
\hline
\end{tabular}

\section{Review of Experimental Agri-industrial Waste-Based Products and Comparison with AGROTESs Panels Thermal Characteristics}

An extensive review of research developed in the field of biomass-based insulation products has recently been proposed by Liu et al. (2017), revealing considerable interest in products for energy savings in buildings, with low environmental impact. Asdrubali et al. (2015) proposed an overview of insulation panels made from natural or recycled materials, still scarcely available on the market, focusing mainly on the thermal characteristics and environmental impact of the products. Abu-Jdayil et al. (2019) offer a review of thermal insulation materials using renewable resources and wastes, and composite materials, both with low environmental impact.

An assessment of insulation panels manufactured from agri-industrial waste and by-products and their relative thermal properties has been resumed in Table 3. Except for a few cases, insulation panels made from natural materials, using agriculture waste or by-products, and from recycled industrial textile materials, were usually found to show interesting specific heat and density. Thermal conductivity results, on the contrary, demonstrated high variation. 
Table 3 Thermal properties of thermal insulation panels made from agricultural and textile production chain waste

\begin{tabular}{|c|c|c|c|}
\hline Agricultural waste-based insulation panels & $\begin{array}{l}\text { Density } \\
\left(\mathrm{kg} / \mathrm{m}^{3}\right)\end{array}$ & $\begin{array}{l}\text { Thermal conductivity } \\
(\mathrm{W} / \mathrm{mK})\end{array}$ & $\begin{array}{l}\text { Heat capacity } \\
(\mathrm{J} / \mathrm{kgK})\end{array}$ \\
\hline \multicolumn{4}{|l|}{ Without added binder } \\
\hline AGROTESs A & 204 & 0.054 & - \\
\hline AGROTESs B & 249 & 0.063 & - \\
\hline Binderless Bagasse particleboards [1] & $250-350$ & $0.049-0.055$ & - \\
\hline Cartonlana - sheep's wool-fibre panels [5] & 142 & 0.040 & - \\
\hline Coconut and Bagasse boards [1] & $250-350$ & $0.046-0.068$ & - \\
\hline Cotton stalk fib. without resin $[17,1]$ & $150-450$ & $0.059-0.082$ & - \\
\hline FITNESs - Sheep's wool-Hemp fibres [13] & 142 & $0.042-0.043$ & - \\
\hline Rice hulls [2] & $148-168$ & $0.046-0.057$ & - \\
\hline Reed panels [2] & $130-190$ & $0.045-0.056$ & 1200 \\
\hline Straw bales $[9,2]$ & 60 & 0.067 & 600 \\
\hline Straw fibre panels [7] & $110-130$ & 0.08 & - \\
\hline Wood waste [6] & $117-158$ & $0.048-0.055$ & - \\
\hline \multicolumn{4}{|l|}{ With added binder } \\
\hline Bagasse particleboards with binder [2] & $70-120$ & 0.046 & - \\
\hline Cattail (Typha) with Methylene binder [11] & $200-400$ & $0.044-0.060$ & - \\
\hline Corn cob with wood glue particleboards [2] & - & 0.10 & - \\
\hline Cotton stalk fib. particleboards with chemical binder [2] & 400 & 0.082 & - \\
\hline Miscanthus giganteus fib., mineral binders [14] & $330-819$ & $0.08-0.1$ & - \\
\hline Durian peel particleboards [2] & 428 & 0.064 & - \\
\hline Durian + Coir-coconut fib. $[10,2]$ & 330 & 0.073 & - \\
\hline Pineapple leaves panels [2] & $178-232$ & $0.035-0.043$ & - \\
\hline Pineapple leaves panels, hot pressed [2] & 338 & 0.057 & - \\
\hline Rice Straw fibre panels with Methylene Resin [16] & $200-350$ & $0.051-0.053$ & - \\
\hline Rice Husk + PBAT/PLA polymers [12] & 378 & 0.08 & $488-560$ \\
\hline Rice husk ashes $[8,2]$ & $350-850$ & $0.14-0.25$ & - \\
\hline Sphagnum moss and rye straw fibres [3] & $156-190$ & $0.044-0.046$ & - \\
\hline Wheat husk + PBAT/PLA polymers [12] & 448 & 0.1 & $675-761$ \\
\hline Wood fibres + PBAT/PLA polymers [12] & 454 & 0.11 & $775-877$ \\
\hline Sunflower piths particle boards [2] & $36-50$ & $0.035-0.15$ & - \\
\hline \multicolumn{4}{|l|}{ Raw materials } \\
\hline Date palm [2] & - & 0.072 & - \\
\hline Oil palm fibres [2] & 100 & 0.055 & - \\
\hline Silkworm cocoons walls [1] & - & $0.011-0.065$ & - \\
\hline Industrial textile waste-based panels & $\begin{array}{l}\text { Density } \\
\left(\mathrm{kg} / \mathrm{m}^{3}\right)\end{array}$ & $\begin{array}{l}\text { Thermal conductivity } \\
(\mathrm{W} / \mathrm{mK})\end{array}$ & $\begin{array}{l}\text { Heat capacity } \\
(\mathrm{J} / \mathrm{kgK})\end{array}$ \\
\hline AGROTESs $\mathrm{C}_{1}$ & 240 & 0.062 & - \\
\hline Recycled cotton and denim [2] & $25-45$ & $0.039-0.044$ & 1600 \\
\hline Recycled Synt. textile scraps $[15,2]$ & 396 & $0.041-0.053$ & - \\
\hline Sunflower stem, cotton textile waste with Epoxy [4] & - & 0.073 & - \\
\hline Textile fibres + PBAT/PLA polymers [12] & 488 & 0.14 & - \\
\hline
\end{tabular}

References: Abu-Jdayil et al. 2019 [1]; Asdrubali et al. 2015 [2]; Bakatovich and Gaspar 2019 [3]; Binici et al. 2013 [4]; Bosia et al. 2015 [5]; Cetiner \& Shea 2018 [6]; Dissanayake et al. 2018 [7]; Gonçalves and Bergmann 2007 [8]; Goodhew et al., 2004 [9]; Khedari et al. 2003 [10]; Luamkanchanaphan et al. 2012 [11]; Muthuraj et al. 2019 [12]; Pennacchio et al. 2017 [13]; Savic et al. 2020 [14]; Valverde et al. 2013 [15]; Wei et al. 2015 [16]; Zhou et al. 2010 [17]. 


\section{Agriculture Waste-Based Panels with Binder Addiction}

Thermal panels produced using chemical or synthetic binders reach a high-density value corresponding, in most cases, also to higher thermal conductivity.

Cattail fibre-based thermal insulating panels with the addition of Methylene Diphenyl Diisocyanate (MDI) as a binder, studied by Luamkanchanaphan et al. (2010), had a thermal conductivity similar to other insulation products made with natural materials already available on the market, accompanied by quite high density.

Panels from rice straw harvested in Jiangsu Province, China, were also manufactured adding an MDI resin, mixed with acetone, and sprayed onto the fibres; $4-\mathrm{cm}$ thick panels were then pressed into a mould, with electromagnetic radiation hot plates (Wei et al. 2015). The panels showed a density range and mean thermal conductivity similar to Cattail panels. The authors noticed that reducing the fibre particle size positively influences the bulk density and the mechanical properties of the panels, while increasing thermal conductivity.

Pineapple leaves panels with natural rubber as a binder showed very interesting results, with density and thermal conductivity increasing when using hot press production techniques (Asdrubali 2015). Despite a $428-\mathrm{kg} / \mathrm{m}^{3}$ density, Durian panels were found to have a medium range thermal conductivity of $0.064 \mathrm{~W} / \mathrm{mK}$ (Asdrubali et al. 2015), while high density panels produced by Muthuraj et al. (2019) from wheat, rice husks, wood fibres, mixed with biodegradable poly-composite resins, all showed quite high $\lambda$ values.

Bakatovich \& Gaspar's (2019) rigid panels made of Sphagnum moss rye straw and reeds, mixed with sodium silicate as a binder, presented highly competitive thermal conductivity with medium density.

\section{Agriculture Waste Panels with no Binder Added}

As in the case of wool fibres for AGROTESs panels, or previous authors' works FITNESs and Cartonlana panels, certain natural waste materials from agricultural production chains contain natural polymers or proteins that can be released and used as a natural binder or resin in manufacturing thermal insulating panels, with no need to resort to synthetic or other binding agents.

Coconut husks, rich in lignin, and bagasse, a by-product of sugar production, containing high percentages of cellulose were used for thermal insulating boards production (Abu-Jdayil et al. 2019) that reached quite high density, which makes them functional also in dynamic thermal performance. Binderless Bagasse particleboards also showed similar thermal features: $250-350 \mathrm{~kg} / \mathrm{m}^{3}$ density and $\lambda$ 0.049-0.055 W/mK (Asdrubali et al. 2015).
Particleboards made from rice hulls showed similar thermal conductivity and lower mean density of $154 \mathrm{~kg} / \mathrm{m}^{3}$. Reeds panels (Asdrubali et al. 2015), largely used in traditional architecture, wood waste used as a binderless loose infill without any mechanical compression in timber frame buildings (Cetiner \& Shea 2018) and rice hull panels (Asdrubali et al. 2015) all showed similar $\lambda$ and medium-low density values, both slightly lower than AGROTESs samples $\mathrm{A}$ and B. Other particleboards made from cotton stalks produced with hot pressing also present interesting nonsteady-state thermal properties with higher variable thermal conductivity, depending on the density reached, ranging between 150 and $450 \mathrm{~kg} / \mathrm{m}^{3}$.

Straw bales, instead, demonstrated $\lambda 0.067 \mathrm{~W} / \mathrm{mK}$ for low-density samples (Goodhew and Griffiths 2005), while other straw panels reported by Dissanayake et al. (2018) show both slightly higher density and thermal conductivity.

The thermal performances of AGROTESs samples A and $\mathrm{B}$ are in line with the mean values reported for panels obtained from waste materials or by-products from agricultural production chains, manufactured without the addition of any binding agent. Heat capacity was found only for few research products and also AGROTESs samples' one have not been obtained from experimental tests, so it has not been reported in the table, although it is expected to be around $1700-1800 \mathrm{~J} / \mathrm{kgK}$, according to the heat capacity of the raw materials used (see Table 4). If confirmed, produced samples would present as highly competitive insulating products, in the examined field, also considering the non-steady-state thermal behaviour, due to their likely high diffusivity.

\section{Industrial Textile Waste Panels}

Literature on textile waste-based insulation panels did not reveal as much material as agri-waste. Binici produced insulating chipboards using cotton textile waste and sunflower stalks mixed with epoxy as a binder, reaching $0.073 \mathrm{~W} / \mathrm{mK}$ thermal conductivity in the better performing sample. Panels made from recycled synthetic textile scraps (Valverde et al. 2013) reached high density and quite low $\lambda$ values, slightly lower than those of AGROTESs sample $\mathrm{C} 1$, which, showed

Table 4 Tentatively calculated heat capacity of AGROTESs samples

\begin{tabular}{ll}
\hline Insulation panels & $\begin{array}{l}\text { Specific heat } \\
\text { capacity [J/ } \\
\text { kgK] }\end{array}$ \\
\hline AGROTESs A (wool fibres/rice straw fibres) & 1715 \\
AGROTESs B (wool fibres/chopped corn) & 1800 \\
AGROTESs C1 (waste wool textile powders) & 1260 \\
\hline
\end{tabular}

References: data retrieved from Verma \& Prasad 2000; Kahr et al. 2012; Liuzzi et al. 2020 
higher thermal conductivity values if compared with other panels found, also due to its lower density.

\section{Applications of AGROTESs Panels in Buildings}

Due to their rigid structure, high density and the satisfactory results of the steady-state thermal laboratory tests performed, AGROTESs panel prototypes have been considered potentially suitable, particularly for the thermal insulation of vertical building envelopes. Being fully compostable materials, produced panels could result particularly interesting for fully dismountable dry construction systems in timber or steel, but they could also find use for the energy retrofit of traditional building systems, making use of full or hollow brick walls technologies.

Each sample produced was tested for application in two different virtual wall stratigraphies, a dry wooden building wall technology and an existing traditional vertical envelope technology, for new construction and for energy retrofit purposes respectively. Both steady-state and dynamic thermal behaviour of all the stratigraphies proposed were calculated, according to UNI EN ISO 13786:2008. The envelope systems considered had already been used by the authors in a previous work (see Savio et al. 2018) to verify the suitability of similar research products for building construction.

During the laboratory tests for the thermal characterisation of AGROTESs samples, it was not possible to deduce their specific heat capacity, so the relative data for each raw material used for samples production, were retrieved from literature (Verma \& Prasad 2000; Kahr et al. 2012; Liuzzi et al. 2020) and web databases (Greenspec.co.uk; Engineeringtoolbox). The tentative specific heat capacity of each AGROTESs samples was obtained from the weighted average of the specific heat capacities of each of the raw materials used in the panels and are reported in Table 4.

\section{Application of AGROTESs in New Dry Building Technologies}

Figure 4a shows a commonly used wooden frame wall technology, in which AGROTESs panels have been considered both as an infill of the wooden frame confined by two plywood panels, and as additional external insulating coating, supported by a steel structure in a ventilated wall system and for an additional inner insulating layer. The wall stratigraphy, with an overall thickness of $0.351 \mathrm{~m}$, was initially completed on the inner side with a double plasterboard layer or with multi-layered plywood panels, but the first dynamic thermal performance results suggested the use of products with higher thermal diffusivity, for the inner layers of the wall stratigraphy. A 2.2-cm natural clay board with 1-cm clay finishing was then chosen to close the wall stratigraphy on the inner side, resulting in a higher inner side periodic areal heat capacity $k_{1}$, meeting the recent indications contained in the CAMs - Criteri Ambientali Minimi/Minimum Environmental Criteria (Legislative Decree 11/10/2017). In the CAMs literature, $k_{l}$ is referred to as Cip, and is suggested as reaching a minimum value of $40 \mathrm{~kJ} / \mathrm{m}^{2} \mathrm{~K}$ in new buildings. The parameter is an indicator of the thermal mass and thermal storage performance of the analysed wall, particularly in summer.

All simulated applications of AGROTESs panels satisfactorily complied with the national standards to be reached in 2021 for vertical building envelopes (Legislative Decree 192/05), which sets the maximum value of thermal transmittance $\mathrm{U}$ at $0.26 \mathrm{~W} / \mathrm{m}^{2} \mathrm{~K}$, for newly constructed buildings. The thickness of the panels used in the simulation was supposed to be $4.5 \mathrm{~cm}$, in accordance with the dimension of other waste wool fibre-based panels, previously produced by the author with a similar procedure (Pennacchio et al. 2017).

As shown in Table 4, the dynamic thermal performances of the simulated wall stratigraphy are largely appreciable in all three scenarios of AGROTESs panels' applications. Decrement factor $f d$. largely below the dimensionless limit of 0.15 , and thermal lag $\varphi$ values between 15.33 and $16.98 \mathrm{~h}$, ensure excellent thermal behaviour in summer (Uni En Iso 13786:2008), while $k_{l}$, as already observed, can meet the most recent pertinent legislation (Legislative Decree 11/10/2017). It can be observed that wall stratigraphy with AGROTESs sample A shows significantly better results in steady-state thermal transmittance performance than in the other two cases, while AGROTESs sample $\mathrm{C} 1$ wall stratigraphy can reach decrement factor values less interesting than the other cases, even if largely below the acceptable limits. The other indicators of the dynamic thermal performance of the wall stratigraphies analysed do not show significant differences.

\section{AGROTESs Use in the Energy Retrofit of Traditional Building Envelope Technologies}

The application of AGROTESs panels has been also verified for energy retrofit purposes. The new panels were tested here, as a thermal coating retrofitting measure, protected by a steel structure ventilated façade system, making use of slate panels as finishing, and as a further insulating layer on the inner side of the wall (see Fig. 4b).

National standards demand a maximum $U$ value of $0.28 \mathrm{~W} / \mathrm{m}^{2} \mathrm{~K}$ (D.lgs 192/05), in case of energy retrofit of vertical opaque envelopes of existing buildings in climatic zone $\mathrm{E}$, for 2021. In order to reach the required $\mathrm{U}$ value, a two-layer thermal coating and a further layer in the inner side of the wall stratigraphy was needed, in all three 
a - Wooden dry wall

1 - clay plaster thickness $1 \mathrm{~cm}$

2 - clay board $2.2 \mathrm{~cm}$

3 - AGROTESs panels $4.5 \mathrm{~cm}$

4 - Wood board $1.25 \mathrm{~cm}$

5 - Water vapor barrier membrane

6 - Wood board $1.5 \mathrm{~cm}$

7 - Steel profile structure

8 - Wood finishing panels

b - Retrofitted traditional wall

1 - Clay plasterthickness $1 \mathrm{~cm}$

2 - Clay board $2.2 \mathrm{~cm}$

3 - AGROTESs panels $5-5.5 \mathrm{~cm}$

4 - Render

5- Hollow bricks inner lining $10 \mathrm{~cm}$

6 - Hollow space $6 \mathrm{~cm}$

7 - Light hollow bricks $20 \mathrm{~cm}$

8 - Cement mortarbased plaste

9 - AGROTESs panels $10-11 \mathrm{~cm}$

10 - Ventilated wall steel structure

11 - Slate tiles finishing

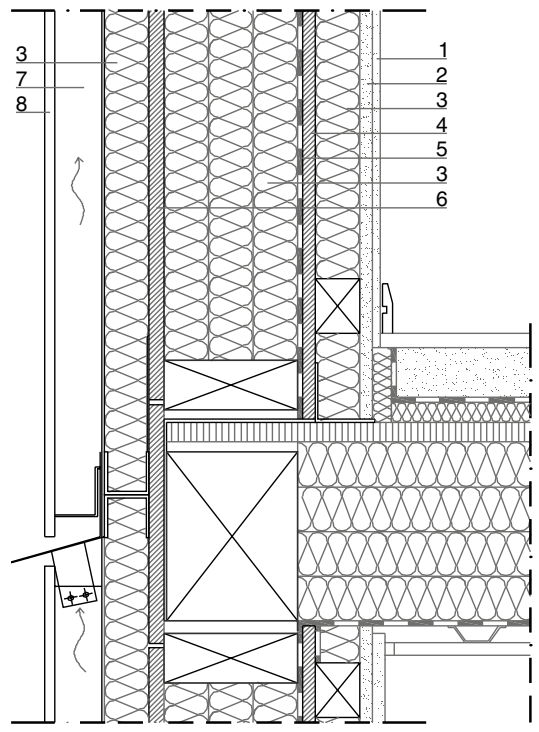

- New wooden structure dray wall stratigraphy

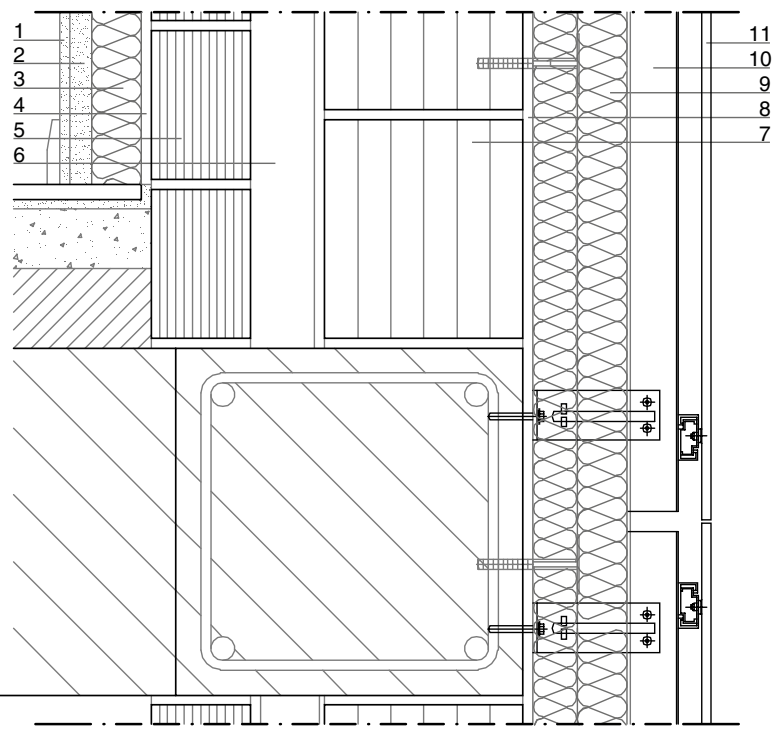

b - Retrofitted traditional wall technology

Fig. 6 AGROTESs panels application in two different vertical envelop technologies: a in a common new dry timber wall technology, and b in the energy retrofit of a traditional wall technology

Table 5 Thermal behaviour of the dry wall stratigraphy proposed, including AGROTESs panels

Table 6 Thermal performance of traditional wall technology retrofitted using AGROTESs panels

\begin{tabular}{llllll}
\hline New wooden dry wall stratigraphy & $\mathrm{U}$ & $\mathrm{fd}$ & $\varphi$ & Yie \\
& {$\left[\mathrm{W} / \mathrm{m}^{2} \mathrm{~K}\right]$} & {$[-]$} & $\begin{array}{l}\varphi \\
{[\mathrm{h}]}\end{array}$ & $\begin{array}{l}\mathrm{k}_{1} \\
{\left[\mathrm{~kJ} / \mathrm{m}^{2} \mathrm{~K}\right]}\end{array}$ \\
\hline AGROTESs A dry wall stratigraphy & 0.213 & 0.086 & 16.90 & 0.018 & 44.4 \\
AGROTESs B dry wall stratigraphy & 0.245 & 0.087 & 16.98 & 0.021 & 45.0 \\
AGROTESs C1 dry wall stratigraphy & 0.238 & 0.121 & 15.33 & 0.029 & 44.6 \\
\hline
\end{tabular}

\begin{tabular}{lllllll}
\hline Retrofitted traditional wall stratigraphy & $\mathrm{s}$ & $\mathrm{U}$ & $\mathrm{fd}$ & $\varphi$ & $\mathrm{Yie}$ & $\mathrm{k}_{1}$ \\
& {$[\mathrm{~cm}]$} & {$\left[\mathrm{W} / \mathrm{m}^{2} \mathrm{~K}\right]$} & {$[-]$} & {$[\mathrm{h}]$} & {$\left[\mathrm{W} / \mathrm{m}^{2} \mathrm{~K}\right]$} & {$\left[\mathrm{kJ} / \mathrm{m}^{2} \mathrm{~K}\right]$} \\
\hline AGROTESs A retrofitted wall stratigraphy & 64.9 & 0.253 & 0.040 & 20.15 & 0.010 & 89.9 \\
AGROTESs B retrofitted wall stratigraphy & 65.2 & 0.264 & 0.032 & 21.50 & 0.008 & 89.9 \\
AGROTESs C1 retrofitted wall stratigraphy & 64.9 & 0.275 & 0.093 & 16.58 & 0.026 & 89.8 \\
\hline
\end{tabular}

proposed scenarios. In the case of AGROTESs A, a 9-cm thick external coating plus a $4.5-\mathrm{cm}$ panel on the inner side, were enough to achieve the required $U$ value. When using both samples B and $\mathrm{C} 1$, the thickness of the panels had to be enhanced to $5.5 \mathrm{~cm}$ and $5 \mathrm{~cm}$ respectively, resulting in an external insulation coating thickness of $11 \mathrm{~cm}$ and $10 \mathrm{~cm}$ respectively. An additional panel on inner side of the wall was also required in both cases (Fig. 6).

Anyway, also when using type A panels, the overall thermal insulation thickness was considered $15 \mathrm{~cm}$, for better comparison reasons and with the aim to reach a lower U value, as the value obtained using 4.5 thick panels was too close to the accepted limit. The resulting thermal performances of the wall stratigraphies retrofitted with the three AGROTESs panels, are shown in Table 5 and Table 6.

In this case, AGROTESs panel A shows the most interesting performance, due to the lower $U$ value, even with a panel thickness of $5 \mathrm{~cm}$, while the retrofit solution including $\mathrm{C} 1$ panels would better work using $5.5-\mathrm{cm}$ thick panels, for a $16.5-\mathrm{cm}$ overall insulation thickness, which would lead to a more comfortable $0.258 \mathrm{~W} / \mathrm{m}^{2} \mathrm{~K} \mathrm{U}$ value.

In all three cases, as to ensure to keep the $\mathrm{k}_{1}$ value at least equal to that of the wall before the retrofit intervention, as required by CAMs (Legislative Decree 11/10/2017), it was necessary to add a 1-cm thick layer of plaster on the inner side of the wall. All un-retrofitted wall configurations previously showed $88.7 \mathrm{~kJ} / \mathrm{m}^{2} \mathrm{~K} \mathrm{k}_{1}$ values. 


\section{Conclusions}

AGROTESs experimental samples showed satisfactory thermal conductivity and quite high bulk density for a thermal insulating material, particularly if compared with similar experimental products made from agri-industrial wastes or by-products manufactured without the addition of binding components (see Table 2). The thermal conductivity values, obtained during the tests performed in laboratory, are still not highly competitive with natural thermal insulating panels currently available on the market, but the registered bulk density combined with the heat capacity assumed on the basis of the raw materials values found in literature, should also ensure good nonsteady-state thermal performances. The bulk density and $\lambda$ value could be eventually further adjusted during future research development: in other research programmes on bio-fibre-based insulation materials (Savic et al. 2020), it has been noticed how the length of the fibres used in the mixture highly influences the thermal performance of the final product. The longer the fibres, the higher the porosity and the ability to retain air of the panels, resulting in a lower thermal conductivity. Shorter fibres, on the contrary, should ensure higher density and increase the mechanical properties. The thermal conductivity of the samples could be eventually improved by the application of calibrated pressure on the fibre mixture during panels' manufacturing, with the aim of favouring the formation of air pores and thereby reducing the bulk density.

As rigid insulation panels, AGROTESs offer good workability, also proving suitable for multiple uses in architecture, both in new construction field, and in the field of energy retrofit of traditional building envelope technologies, adapting to traditional anchorage systems. In both cases, when applied in common wall stratigraphies, the new panels quite easily met the national legislation requirements in terms of thermal performance for opaque vertical envelopes and the recent recommendations of CAMs (Minimum Environmental Criteria), particularly regarding the thermal inertia of the inner layers of envelopes (Legislative Decree 11/10/2017). Moreover, AGROTESs panels, as agri-industrial waste-based materials, do not contain noxious components for human health thus fulfil the requirements contained in paragraph 2.4.2.9 of Legislative Decree 11/10/2017 for thermal and acoustic insulating products, adopting CAMs recommendations.

AGROTESs panels could also find use as medium-high density insulation products in a mass-spring-mass system for thermal insulation coatings, with higher acoustic insulation performances.

For further research development, the manufacturing of full-scale panels would confirm the applicability of the industrial production process already studied for previous authors' works, while mechanical strength tests would be needed to fully assess the physical characteristics of the products.

Considering the wool fibre-content, the rough appearance of one of the main sample sides and the very interesting performances already obtained with FITNESs and Cartonlana panels (Bosia et al. 2015; Pennacchio et al. 2017), high acoustic absorption performances are expected. Appropriate laboratory tests would open the way for further uses of the panels for acoustic absorption in large open indoor environments.

Acknowledgements The authors gratefully acknowledge Agrindustria Tecco s.r.l. (Cuneo, Italy) for the waste materials supply used in the samples production and Arch. Fabrizio Angaramo who collaborated to our research during his graduation work.

Author contribution LS studied the "open recipe" concept for lowenvironmental-impact insulation panels and analysed the thermal performance of AGROTESs panels. RP determinated the thermal performance, reviewed the experimental agri-industrial waste-based products and comparison with AGROTESs panels thermal characteristics and analysed the applications of AGROTESs panels in circular economy perspectives, also determining wall stratigraphies thermal performances. AP developed the AGROTESs panels production process. VM developed the research background analysis and analysed applications of AGROTESs panels in circular economy perspectives. DB coordinated the research team, selected the waste materials for AGROTESs panels production developed the critical conclusions. All authors read and approved the final manuscript.

Funding Research funds from Politecnico di Torino.

Data availability The datasets generated during and/or analysed during the current study are available from the corresponding author on reasonable request.

\section{Declarations}

Competing interests The authors declare no competing interests.

Open Access This article is licensed under a Creative Commons Attribution 4.0 International License, which permits use, sharing, adaptation, distribution and reproduction in any medium or format, as long as you give appropriate credit to the original author(s) and the source, provide a link to the Creative Commons licence, and indicate if changes were made. The images or other third party material in this article are included in the article's Creative Commons licence, unless indicated otherwise in a credit line to the material. If material is not included in the article's Creative Commons licence and your intended use is not permitted by statutory regulation or exceeds the permitted use, you will need to obtain permission directly from the copyright holder. To view a copy of this licence, visit http://creativecommons.org/licenses/by/4.0/.

\section{References}

Abu-Jdayil B, Mourad AH, Hittini W, Hassan M, Hameedi S (2019) Traditional, state-of-the-art and renewable thermal building 
insulation materials: an overview. Construction and Building Materials 214 (2019) 709-735, Elsevier.

Asdrubali F, D'Alessandro F, Schiavoni S (2015) A review of unconventional sustainable building insulation materials. Sustainable Materials and Technologies 4:1-17, Elsevier.

Bakatovich A, Gaspar F (2019) Composite material for thermal insulation based on moss raw material. Construction and Building Materials, 228, 116699, Elsevier.

Binici H, Eken M, Kara M, Dolaz M (2013) An environment-friendly thermal insulation material from sunflower stalk, textile waste and stubble fibers. In: Proceedings of the International Conference on Renewable Energy Research and Applications. 20-23 October 2013. Madrid, Spain.

Bosia D, Savio L, Thiebat L, Patrucco A, Fantucci F, Piccablotto G, Marino D (2015) Sheep wool for sustainable architecture. Energy Procedia 78:315-320, Elsevier https://doi.org/10.1016/j.egypro. 2015.11.650.

Cetiner I, Shea AD (2018) Wood waste as an alternative thermal insulation for buildings. Energy \& Buildings 168, 374-384, Elsevier.

Dissanayake DGK, Weerasinghe DU, Kalpage KMDMP (2018) Developing a compression moulded thermal insulation panel using postindustrial textile waste. Waste Management 79:356-361, Elsevier.

ECORYS (2014), Resource efficiency in the building sector, Final Report, Rotterdam. Available at: https://ec.europa.eu/envir onment/topics/waste-and-recycling/construction-and-demolitionwaste_en\#ecl-inpage-450. Accessed 5 May 2021.

European Parliament (2015), Circular economy: definition, importance and benefits. Available at: https://www.europarl.europa.eu/news/ en/headlines/economy/20151201STO05603/circular-economydefinition-importance-and-benefits. Accessed 26 Apr 2021.

European Commission (2019), Going climate-neutral by 2050 - a strategic long-term vision for a prosperous, modern, competitive and climate-neutral EU economy. Available at: op.europa.eu/ en/publication-detail/-/publication/92f6d5bc-76bc-11e9-9f0501aa75ed71a1. Accessed 5 May 2021.

Gonçalves MRF, Bergmann CP (2007) Thermal insulators made with rice husk ashes: production and correlation between properties and microstructure. Constr. Build. Mater. 21:2059-2065, Elsevier. https://doi.org/10.1016/j.conbuildmat.2006.05.057.

Goodhew S, Griffiths R (2005) Sustainable earth walls to meet the building regulations. Energy Build 37:451-459. https://doi.org/ 10.1016/j.enbuild.2004.08.005

Khedari J, Charoenvai S, Hirunlabh J (2003) New insulating particleboards from durian peel and coconut coir. Build Environment 38:435-441

Liu LF, Li HG, Lazzaretto A, Manente G, Tong CY, Liu QB, Li NP (2017) The development history and prospects of biomass-based insulation materials for buildings. Renewable and Sustainable Energy Reviews 69: 912-932, Elsevier.

Liuzzi S, Rubino C, Martellotta F, Stefanizzi P, Casavola C, Pappalettera G (2020) Characterization of biomass-based materials for building applications: the case of straw and olive tree waste. Industrial Crops \& Products 147:112229, Elsevier.

Luamkanchanaphan T, Chotikaprakhan S, Jarusombati S (2012) A study of physical, mechanical and thermal properties for thermal insulation from narrow-leaved cattail fibers, APCBEE Procedia 1:46-52. Elsevier. https://doi.org/10.1016/j.apcbee.2012.03.009

MATTM (2021), I criteri ambientali minimi. Available at: https://www. minambiente.it/pagina/i-criteri-ambientali-minimi, 17A07439, GU Serie Generale n.259 del 06-11-2017. Accessed 29 Apr 2021.
Muthuraj R., Lacoste C, Lacroix P, Bergeret A (2019) Sustainable thermal insulation biocomposites from rice husk, wheat husk, wood fibers and textile waste fibers: elaboration and performances evaluation. Industrial Crops \& Products 135:238-245, Elsevier.

Panyakaew S, Fotios S (2011) New thermal insulation boards made from coconut husk and bagasse, Energy Build. 43:1732-1739, Elsevier.

Pennacchio R, Savio L, Bosia D, Thiebat F, Piccablotto G, Patrucco A, Fantucci S (2017) Fitness: sheep-wool and hemp sustainable insulation panels. Energy Procedia 111:287-297, Elsevier.

Savic A, Antonijevic D, Jelic I, Zakic D (2020) Thermomechanical behaviour of bio-fiber composite thermal insulation panels. Energy \& Buildings 229:110511, Elsevier.

Savio L, Bosia D, Patrucco A, Pennacchio R (2018) Applications of Building Insulation Products Based on Natural Wool and Hemp Fibers. In: Fangueiro R, Rana S (ed) Advances in Natural Fibre Composites, Raw Materials, Processing and Analysis, 1st edn. Springer International Publishing 237-247.

Savio L, Bosia D, Manni V, Pennacchio R, Thiebat F, Patrucco A (2019) Natural fibers insulation panels: an adaptive production. In: Barbero S (ed) RSD7 2018 Relating systems thinking and design $7^{\text {th }}$ symposium, Sistemic Design Association 121-132.

UNEP - United Nations Environment Programme (2020), 2020 Global Status Report for Buildings and Construction: Towards a Zeroemission, Efficient and Resilient Buildings and Construction Sector. Nairobi. Available at: https://globalabc.org/news/launched2020-global-status-report-buildings-and-construction. Accessed 5 May 2021.

Valverde IC, Castilla LH, Nuñez DF, Rodriguez-Senín E, de la Mano Ferreira R (2013) Development of new insulation panels based on textile recycled fibers, Waste Biomass Valoriz. 4:139-146, Springer, https://doi.org/10.1007/s12649-012-9124-8.

Verma RC, Prasad S (2000) Mechanical and thermal properties of Maize. Journal of Food Science and Technology 37, 5:500-505, Springer.

Wei K, Lv C, Chen M, Zhou X, Dai Z, Shen D (2015) Development and performance evaluation of a new thermal insulation material from rice straw using high frequency hot-pressing. Energy and Buildings 87:116-122, Elsevier.

Zhou XY, Zheng F, Li HG, Lu CL (2010) An environment-friendly thermal insulation material from cotton stalk fibers, Energy Build. 42:1070-1074, Elsevier.

Kahr H, Jäger A, Lanzerstorfer C (2012) Bioethanol Production from Steam Explosion Pretreated Straw. In: Pinheiro Lima MA (edn) Bioethanol. In Tech. ISBN: 978-953-51-0008-9.

\section{Web sites}

Greenspec.co.uk - https://www.greenspec.co.uk/building-design/insul ation-materials-thermal-properties/. Accessed 8/10/2021

Engineeringtoolbox - https://www.engineeringtoolbox.com/specificheat-solids-d_154.html. Accessed 8/10/2021

Publisher's Note Springer Nature remains neutral with regard to jurisdictional claims in published maps and institutional affiliations. 